\title{
Fluid inertia damper using MR fluid with a long spiral bypass pipe
}

\author{
Taichi MATSUOKA*, Kazuhiko HIRAMOTO**, Katsuaki SUNAKODA***, \\ Naoto ABE* and Pei-Yang LIN**** \\ *School of Science and Technology, Meiji University \\ 1-1-1 Higashimita, Tama-ku, Kawasaki-shi, Kanagawa 214-8571, Japan \\ E-mail: matsuoka@meiji.ac.jp \\ ${ }^{* *}$ Graduate School of Science and Technology, Niigata University \\ 8050 Ikarashi 2-no-cho, Nishi-ku, Niigata-shi, Niigata 950-2181, Japan \\ *** Professor Emeritus of Akita University \\ 1-1 Tegatagakuen-machi, Akita-shi, Akita 010-8502, Japan

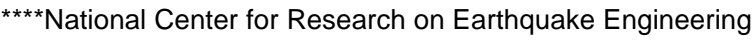 \\ 200, Sec. 3, HsinHai Rd., Taipei 106, Taiwan, R.O.C.
}

Received 18 December 2015

\begin{abstract}
An inertia damper with a long spiral bypass pipe was developed in order to obtain a series inertia effects for vibration suppression of structures in practical use. The damper comprised a cylinder, piston, and MR fluid. The gap was spirally formed around the outside of a cylinder, and acted as a long bypass pipe. MR fluid is well known for its changeable damping effect, but the mass of the fluid is the focus of this study. It is obvious from previous studies that a fluid inertia effect is caused by quick motion in the long bypass pipe, and it depends on the length of the bypass pipe, compression ratio of area, and density. A large inertia effect can be derived if the fluid has a heavy mass. In order to confirm the inertia effect, a prototype damper was manufactured, and resisting force characteristics were measured. Seismic response tests using a 3-story structure were then performed using a shaking table with the damper installed. Each story of the structure had a height of $3 \mathrm{~m}$, and a weight of 6 tons with a total height of $9 \mathrm{~m}$ and a total weight of 18 tons. Several types of earthquakes were input, and the response acceleration, relative displacement, and reaction force were measured. Finally the effects of vibration reduction were confirmed experimentally, and a feasibility study was discussed.
\end{abstract}

Key words : Vibration control device, Vibration control, Damping, Damper, MR fluid, Series inertia mass

\section{Introduction}

Many vibration control devices have been developed and used in practice for the purpose of vibration energy dissipation. In such devices, fluid-type dampers using oil and air, known as oil damper and air damper, are very useful for obtaining a damping effect and are comparatively easy to use; therefore they are used in many fields. As a type of fluid, Magneto-Rheological fluid (hereafter, designated as MR fluid) is also used in dampers instead of oil. The fluid-type damper using MR fluid (known as MR damper) can have the advantage of controllable damping, which can be obtained by virtually changing the viscosity of the fluid because the yielding shear stress of the fluid can be switched by means of a magnetic field (Dyke, et al., 1996, Spencer, et al., 1997, Yang, et al., 2002). MR fluid is a magnetic colloidal solution that comprises oil and small iron particles with surfactants and it has a heavier density than other fluids. Meanwhile, the authors have developed some dampers with an inertia effect to provide a damping effect. An electromagnetic-type damper using a ball screw mechanism can have an inertia effect using a flywheel (Matsuoka, et al., 2007, Sunakoda, et al., 2009, Hiramoto, et al., 2012, Nakamura, et al., 2014), and a vibration suppression device using a fluid can utilize the fluid's inertia (Sunakoda and Matsuoka, 2006, Matsuoka and Sunakoda, 2009). The inertia effect of the damper is to act as a series inertia mass to a primary mass when the damper is installed in a normal 1DOF 
system, and it can make a natural frequency shift towards low frequency and cut off vibration at the anti-resonance frequency. This concept was previously patented by Okumura (2005). Dampers with an inertia effect have been developed by many researchers, e.g., a mechanical snubber (Chiba and Kobayashi, 1984, Kawaguchi, et al., 1991), a pump damper (Kawamata and Onuma, 1986), and a rotary damping tube (Furuhashi and Ishimaru, 2004, Saito, et al., 2007). Furthermore, there are a few studies on the variable inertia effects (Ullman and Velkoff, 1979), a mechanical-type damper using a flywheel (Ohmata and Miyanaga, 1991), an electrical-type damper using impedance matching (Kato and Ito, 1990) or LCR circuits (Isoda, 2008), and a fluid-type damper (Matsuoka, 2011). In this study, the authors developed a fluid inertia damper of $20 \mathrm{kN}$ capacity by utilizing the heavy density of the MR fluid in order to practically apply an inertia effect to the damper. The inertia effect is caused by the quick movement of fluid in a long bypass pipe. The technique of using an inertia effect in a long spiral bypass pipe was patented by Teramura and Yamaguchi (1999), but it has not yet been in the practical application phase and was not accomplished by using MR fluid. In this paper, a proto-type of the fluid inertia damper is designed and manufactured. The theory of inertia and damping effects in cases having a spiral bypass pipe is introduced. To evaluate the dynamic properties of the damper, resisting force characteristics were measured and compared with the theoretical results. Subsequently, to confirm the effects of the vibration reduction for structures, seismic vibration tests were performed using a shaking table at National Center for Research on Earthquake Engineering (NCREE) with the damper installed on the first floor of 3-story benchmark structure. Each story of the structure had a height of $3 \mathrm{~m}$ and a weight of 6 tons, with a total height of $9 \mathrm{~m}$ and a weight of 18 tons. The effects are estimated both experimentally and numerically, and finally a feasibility of the damper is discussed.

\section{Specification}

The design diagram of a fluid inertia damper is shown in Fig. 1, and its design parameters are listed in Table 1. It is expected that the damper has a maximum load capacity of $20 \mathrm{kN}$. The damper comprises a cylinder, piston, cylinder blocks, flange, and rod end. The cylinder, piston and cylinder blocks are made of SS400 structural steel. The cylinder comprises two parts: an inner cylinder and an outer cylinder. A rectangular gap that is $11 \mathrm{~mm}$ deep and $11 \mathrm{~mm}$ wide is spirally formed on the outside of the inner cylinder with 11 turns and a $20 \mathrm{~mm}$ pitch. The inner cylinder is inserted in to the outer cylinder with an interference fit. The spiral gap acts as a long bypass pipe, such as an orifice. The fluid, LORD Co. MRF-122EG, which is a density $2,280 \mathrm{~kg} / \mathrm{m}^{3}$, is poured into the cylinder and bypass pipe through tapered screw holes. The volume of fluid used is about 1.8 litters. Rubber seals are placed between the piston, cylinder, and cylinder block for leak proofing, and a backup ring is also inserted into the piston head to prevent compression by the weight of the piston itself. The fluid inertia effect is caused by the fluid moving quickly through the long bypass pipe when the piston is pushing fluid out of the cylinder. The damper has $90 \mathrm{~mm}$ stroke and weighs about $40 \mathrm{~kg}$ including the fluid.

\section{Theory}

To introduce the resisting force characteristics of the damper, a conceptual sketch of the cylinder and gap is shown in Fig. 2. The damper has the characteristics of an inertia force, damping force, and friction force. When the

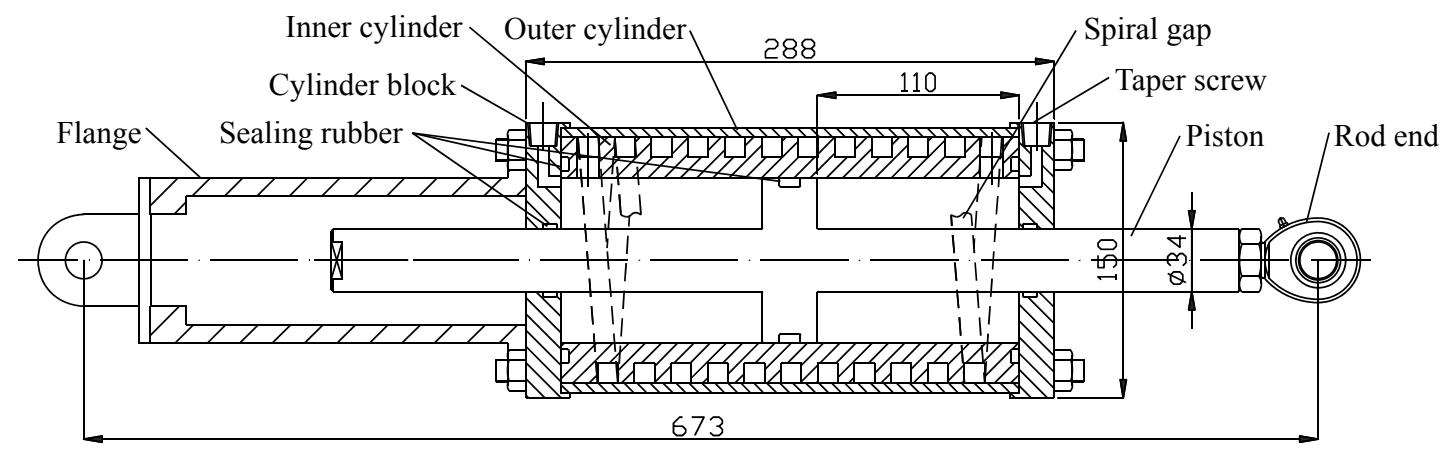

Fig. 1 Design diagram of the fluid inertia damper. The damper has load capacity of $20 \mathrm{kN}$. A rectangular gap is spirally formed on the outside of the inner cylinder, shown as dotted lines, which acts as a long bypass pipe. 
displacement of the piston is defined as $u$, the total resisting force $F$ is given by

$$
F=F_{m}(\ddot{u})+F_{d}(\dot{u})+F_{r} \operatorname{sign}(\dot{u})
$$

where $F_{m}$ is defined as the inertia force, which is proportional to the acceleration; $F_{d}$ is the damping force, which is proportional to the velocity; and $F_{r}$ is the friction force of the damper, respectively. The last term of Eq. (1) shows the sign function, which gives 1 within positive velocity and -1 within negative velocity, otherwise 0 .

\subsection{Inertia effect}

The inertia effect was theoretically introduced in previous papers (Sunakoda, et al., 2006, Matsuoka and Sunakoda, 2009). The kinetic energy of the fluid in the bypass pipe $T$ is defined as

$$
T=\frac{1}{2} m \dot{y}^{2}
$$

where $m$ is the mass of the fluid in the bypass pipe and $y$ is the displacement of the fluid. From the continuity equation, a fluid volume that is pushed out from the cylinder should be equal to the volume that is introduced into the bypass pipe, which is

$$
A_{o} y=A_{p} u
$$

where $A_{p}$ and $A_{o}$ are the cross-sectional areas of the piston and bypass pipe and become $\pi\left(D_{1}{ }^{2}-D_{2}^{2}\right) / 4$ and $b h$, respectively. $D_{1}$ and $D_{2}$ are the diameters of the cylinder and piston rod, and $b$ and $h$ are the width and depth of the rectangular gap, respectively. The mass of the fluid in the bypass pipe is expressed by

$$
m=\rho A_{o} L
$$

where $\rho$ is the density of the fluid, and $L$ is the length of the bypass pipe. $L$ is geometrically given by Pythagoras' theorem and becomes

Table 1 Design parameters of the fluid inertia damper.

\begin{tabular}{lll}
\hline Diameter of the cylinder & $D_{1}$ & $90 \mathrm{~mm}$ \\
Diameter of the piston rod & $D_{2}$ & $34 \mathrm{~mm}$ \\
Pitch center diameter of the gap & $D_{p}$ & $123 \mathrm{~mm}$ \\
Width of the gap & $b$ & $11 \mathrm{~mm}$ \\
Height of the gap & $h$ & $11 \mathrm{~mm}$ \\
Spiral pitch & $L_{p}$ & $20 \mathrm{~mm}$ \\
Number of spiral turn & $N$ & 11 turns \\
Total length of the bypass pipe & $L$ & $4.26 \mathrm{~m}$ \\
Volume of the fluid & & $1.79 \times 10^{-3} \mathrm{~m}^{3}$ \\
Stroke & & $\pm 90 \mathrm{~mm}$ \\
Total weight & & $40 \mathrm{~kg}$ \\
\hline Density of the MR fluid & $\rho$ & $2,280 \mathrm{~kg} / \mathrm{m}^{3}$ \\
Viscosity of the MR fluid & $\mu$ & $0.28 \mathrm{Pas}$ \\
\hline
\end{tabular}

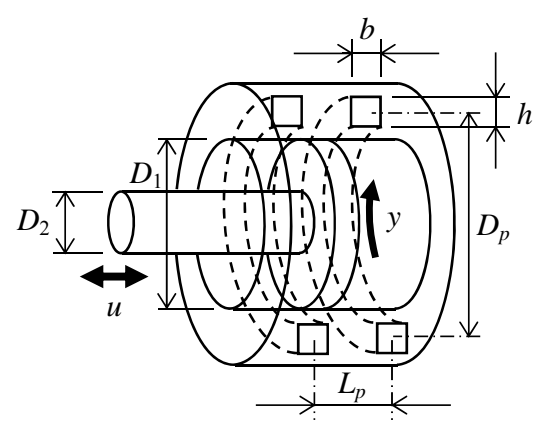

Fig. 2 Conceptual sketch of the cylinder and gap. 


$$
L=N \sqrt{\left(\pi D_{p}\right)^{2}+L_{p}^{2}}
$$

where $N$ is the number of spiral turns, $D_{p}$ and $L_{p}$ are the pitch center diameter and pitch of the spiral gap, respectively. Substituting Eqs. (3), (4), and (5) into Eq. (2) and using Lagrange's equation of motion, the inertia force $F_{m}$ is given by

$$
F_{m}=\rho A_{o} L \alpha^{2} \ddot{u}
$$

and the series inertia mass $m_{d}$ is defined as a modulus that is related to the acceleration $\ddot{u}$ and given by

$$
m_{d}=\rho A_{o} L \alpha^{2}
$$

where $\alpha$ is the compression ratio of the cross-sectional areas between the piston and bypass pipe, which becomes $A_{p} / A_{0}$. Therefore, it is noted from Eq. (6) that the inertia effect is proportional to the compression ratio squared, the density of the fluid, and the length of the bypass pipe.

\subsection{Damping effect}

The damping effect of MR damper using a bypass pipe was given in a past study (Sodeyama, et al., 2004), but the theory was in the case of a straight bypass pipe. In this research, a damping force in the case of a spiral bypass pipe is introduced. The damping force $F_{d}$, which is caused by a pressure drop in laminar flow is generally given by Bernoulli's equation, but it is further arranged in the case of a bent pipe and defined as

$$
F_{d}=\frac{1}{2} \zeta \rho A_{p} \dot{y}^{2}
$$

where $\zeta$ is the coefficient of head loss for a whole spiral pipe. When $R_{e}(d / 2 R)^{2}$ is smaller than 91 , the coefficient of head loss for a single bent pipe of $90^{\circ}$, which denotes $\zeta_{1}$, is given by (Ito, 1959)

$$
\begin{aligned}
& \zeta_{1}=0.00873 \beta \theta \lambda_{c} \frac{2 R}{d} \\
& \beta=0.95+4.42\left(\frac{R}{d}\right)^{-1.96}
\end{aligned}
$$

where $R_{e}$ is the Reynolds number, which is $\rho d \dot{y} / \mu ; R$ is the bend radius of the pipe, which becomes $D_{p} / 2 ; \theta$ is the bend angle; $\mu$ is the viscosity of the fluid; and $d$ is a hydraulic equivalent diameter. In general, the hydraulic diameter is defined as 4 times the cross-sectional area per wetted perimeter, which becomes $4 b h /(2 b+2 h)$. However, the hydraulic equivalent diameter in the case of rectangular duct is given by Huebscher's equation (1948) and defined as

$$
d=1.3 \frac{(b h)^{0.625}}{(b+h)^{0.25}}
$$

It is noted from Eq. (11) that the hydraulic equivalent diameter increases by about $10 \%$ to the initial hydraulic diameter in this case. $\lambda_{c}$ is the friction coefficient of a bent pipe and is defined as

$$
\lambda_{c}=\frac{21.5 K}{\left(1.56+\log _{10} K\right)^{5.73}} \lambda
$$

where $K$ is the Dean number, which denotes the centrifugal effects of the eddy flow in a curved pipe. $\lambda$ is the friction coefficient of a straight pipe under laminar flow and is defined as $64 / R_{e}$. The relationship between the Reynolds number $R_{e}$ and Dean number $K$ is given by

$$
K=R_{e} \sqrt{\frac{d}{2 R}}
$$

It is assumed that the long spiral bypass pipe is a series of continuous bends. According to a previous study on loss factors in a coil pipe (Shimizu, et al., 1982), it was found that a mutual interference coefficient of bends $\eta$ becomes about 0.4 in the case of continuous bends, and is given by 


$$
\eta=\frac{\zeta}{n \zeta_{1}}
$$

where $n$ is a number of bends, which becomes $360 N / 90$ in this case. It is also known that the mean flow velocity in the case of a bent pipe decreases by about $60 \%$ to the velocity of a straight pipe (Ito, 1987).

In fact, the damping effect has an approximately quadratic function relationship to the velocity, and the damping coefficient $c_{d}$ is derived by $F_{d} / \dot{u}$.

\section{Dynamic properties}

To evaluate the dynamic properties of the damper, the resisting force characteristics were measured. The damper was attached to a fixed wall and a servo actuator through a load cell, and the force and displacement were measured when the actuator was forcibly excited by a sinusoidal wave with a frequency from 0.25 to $1.5 \mathrm{~Hz}$ and amplitude of 20 to $50 \mathrm{~mm}$. In the performed tests, the perpendicular load on the damper due to its own weight was canceled by hanging it using a wire rope and eye bolt. The viscosity of the MR fluid was measured before the test using a viscometer and was determined as 0.28 Pas.

The experimental results together with the theoretical results, which were calculated by Eq. (1), are shown in Fig. 3. It is obvious from this figure that the damper can have an inertia effect, shown as a left-rising straight line that increases with increasing frequency, and that the damping effect has an oval shape. The series inertia mass $m_{d}$ becomes 2,385 kg from Eq. (7), and the damping coefficient $c_{d}$ becomes approximately $(143|\dot{u}|+34.8) \mathrm{kNs} / \mathrm{m}$ from Eq. (8), which is linearly proportional to the velocity. The friction force $F_{r}$ was comparatively small and identified as approximately $100 \mathrm{~N}$ from the experimental results. The experimental results agreed well with the theoretical results, and the theory of inertia and the damping effect are confirmed. The L-shaped fixed wall, which comprised steel plates of $24 \mathrm{~mm}$ thick and ribs, elastically deformed slightly under the heavy load. Since a harmonic rotating motion occurred under high frequency due to the centrifugal force of the fluid flow, it seems that the experimental results were partially influenced as waveforms.
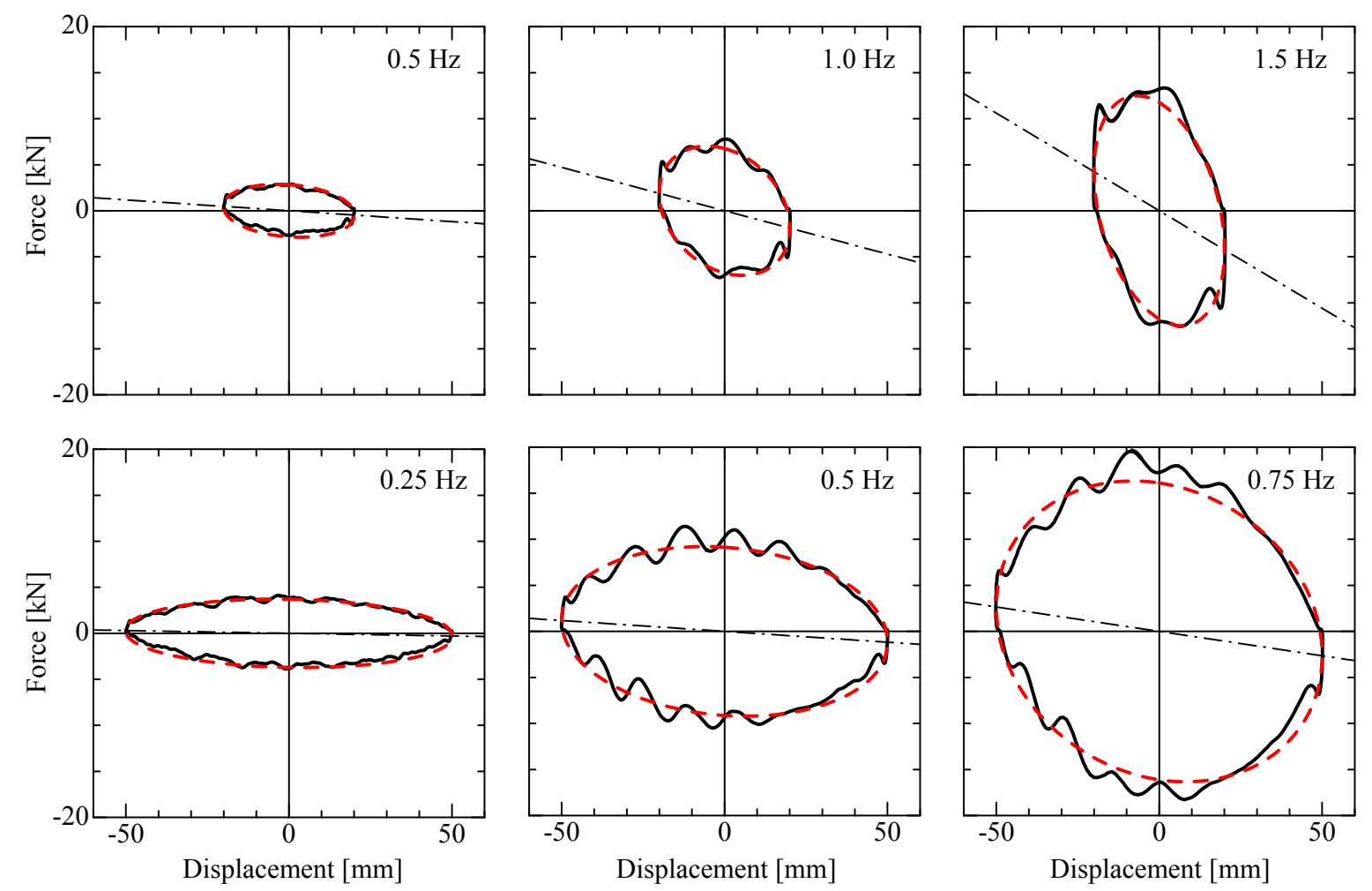

Fig. 3 Resisting force characteristics. -: Exp., - -: Cal. A left-rising slope, as a broken line, indicates the inertia effect that was derived from Eq. (7). The inertia and damping effects increase with increasing frequency. The experimental results agree with the theoretical results. 


\section{Seismic vibration tests}

In order to confirm effects of vibration reduction of the damper for real structures, seismic vibration tests were performed on a 3-story benchmark structure. The 3-story structure had height of $3 \mathrm{~m}$, width of $3 \mathrm{~m}$, span of $2 \mathrm{~m}$, weight of 6 tons per story, and was $9 \mathrm{~m}$ high. Its total weight was 18 tons, as shown in Fig. 4 . The structure was placed on a shaking table, which was $5 \mathrm{~m} \times 5 \mathrm{~m}$ square. Added masses were applied to each story. The damper was installed between the base and first floor only, using a chevron brace. The series inertia mass of the damper was arranged to be about $10 \%$ of the total mass of the structure, and the actual mass ratio $m_{d} /\left(m_{1}+m_{2}+m_{3}\right)$ became 0.13 . These tests were operated by NCREE in Taiwan. Four types of earthquake were applied horizontally by the shaking table: Imperial Valley earthquake in 1940 (USA); El Centro north-south component, Southern Hyogo prefecture earthquake in 1995 (Japan); Japan Meteorological Agency Kobe north-south component, and two kinds of Chi-Chi earthquake in 1999 (Taiwan); TCU-84 and TCU-129, in which the maximum acceleration was normalized to be from 1 to $6 \mathrm{~m} / \mathrm{s}^{2}$. The wave of TCU-84 had a low dominant frequency and comparatively long period component. Conversely, the wave of TCU-129 had a wide band of frequency component. The response acceleration, relative displacement of each story and reacting forces of the damper were measured by accelerometers, linear variable displacement transducers, and a load cell, respectively. The tests were stopped at the acceleration level where the relative displacements between each story exceeded $50 \mathrm{~mm}$.

An analytical model of the 3-story structure is shown in Fig. 5, and its physical parameters are listed in Table 2. Stiffness $k_{i}$ and structural damping coefficient $c_{i}$ were identified from the response acceleration of each story without the damper when a random wave with white noise was input (Nakamura, et al., 2000). The equation of motion of the 3 -story structure is given in a matrix form as

$$
[M]\{\ddot{u}\}+[C]\{\dot{u}\}+[K]\{u\}=-\{m\} \ddot{x}_{0}
$$

where $x_{0}$ is an input displacement of the shaking table, and $M, K, C$ are the mass, stiffness, and damping matrices, which are defined as

$$
\begin{aligned}
& {[M]=\left[\begin{array}{cccc}
m_{b}+m_{d} & -m_{d} & 0 & 0 \\
-m_{d} & m_{1}+m_{d} & 0 & 0 \\
0 & m_{2} & m_{2} & 0 \\
0 & m_{3} & m_{3} & m_{3}
\end{array}\right], \quad[K]=\left[\begin{array}{cccc}
k_{b} & 0 & 0 & 0 \\
0 & k_{1} & -k_{2} & 0 \\
0 & 0 & k_{2} & -k_{3} \\
0 & 0 & 0 & k_{3}
\end{array}\right], \quad[C]=\left[\begin{array}{cccc}
c_{d} & -c_{d} & 0 & 0 \\
-c_{d} & c_{1}+c_{d} & -c_{2} & 0 \\
0 & 0 & c_{2} & -c_{3} \\
0 & 0 & 0 & c_{3}
\end{array}\right]} \\
& \{u\}=\left\{\begin{array}{llllll}
u_{b} & u_{1} & u_{2} & u_{3}
\end{array}\right\}^{T}, \quad\{m\}=\left\{\begin{array}{lllll}
m_{b} & m_{1} & m_{2} & m_{3}
\end{array}\right\}^{T}
\end{aligned}
$$

where $x_{i}, m_{i}, k_{i}$, and $c_{i}$ are the absolute displacement, mass, stiffness and structural damping coefficient of the $i$-th story, respectively. The relative displacement of the $i$-th story is defined as $u_{i}=x_{i}-x_{i-1}$, and $u_{b}=x_{b}-x_{0}$. It is assumed that the stiffness $k_{b}$ is defined as the equivalent stiffness of a fixed wall in order to consider elastic deformation and is determined from the experimental results by trial and error. Moreover, $x_{b}$ is the absolute displacement of an additional degree of freedom, and $m_{b}$ is an auxiliary mass which becomes zero in the calculations. The analytical results were derived by Matlab using input acceleration data, which was recorded for every test. The natural frequency in the 1st mode was calculated by modal analysis and became $1.0 \mathrm{~Hz}$. The modal damping ratio of the 1 st natural frequency was $0.4 \%$ without the damper and $8 \%$ with the damper as a maximum. The surface temperature of the outer cylinder was measured after every test using an infrared radiation thermometer and was maintained at a uniform ambient temperature of $22^{\circ} \mathrm{C}$.

The experimental results of the time history waves of seismic responses together with the analytical results at levels that are comparable with cases in which dampers installed and not installed are shown in Figs. 6, 7, 8 and 9. Peak accelerations and relative displacements, which are related to the input acceleration, are plotted in Figs. 10 and 11, and are shown in Table 3. The peak acceleration of the damper installed in the case of El Centro and TCU-129 decreased about $3 / 5-1 / 2$ to that of no damper installed, and the relative displacement decreased by about $1 / 2$. Conversely, the peak acceleration decreased by about $1 / 2$, whereas the relative displacements were damped down by $2 / 3-2 / 5$ in the cases of Kobe and TCU-84. The damper seems to be more vibration suppressive for seismic motions having a long period component like Kobe and TCU-84 than the others, which include a high dominant frequency such as El Centro 


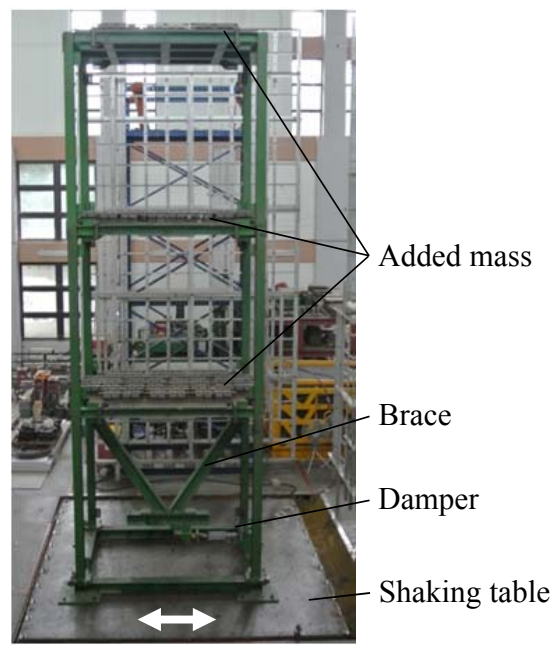

Fig. 4 Seismic vibration test setup. 3-story structure with damper set on a shaking table.

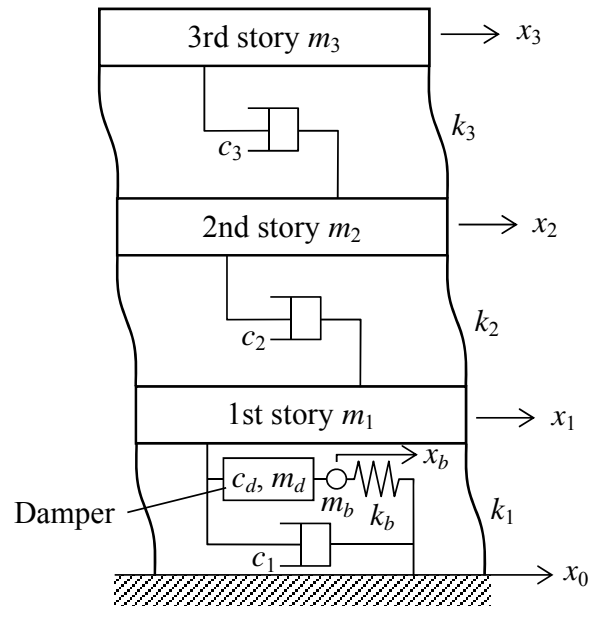

Fig. 5 Analytical model of 3-story structure.

Table 2 Physical parameters of 3-story structure.

\begin{tabular}{lll}
\hline Height & & $9 \mathrm{~m}$ \\
Width & & $3 \mathrm{~m}$ \\
Depth & & $2 \mathrm{~m}$ \\
Total weight & & $18,000 \mathrm{~kg}$ \\
Weight per story & $m_{i}$ & $6,000 \mathrm{~kg}$ \\
1st natural frequency & & $1.0 \mathrm{~Hz}$ \\
\hline Stiffness & $k_{1}$ & $1.257 \times 10^{6} \mathrm{~N} / \mathrm{m}$ \\
& $k_{2}$ & $1.188 \times 10^{6} \mathrm{~N} / \mathrm{m}$ \\
& $k_{3}$ & $1.069 \times 10^{6} \mathrm{~N} / \mathrm{m}$ \\
& $k_{b}$ & $3.5 \times 10^{6} \mathrm{~N} / \mathrm{m}$ \\
\hline Damping coefficient & $c_{1}$ & $3.386 \times 10^{3} \mathrm{Ns} / \mathrm{m}$ \\
& $c_{2}$ & $3.920 \times 10^{3} \mathrm{Ns} / \mathrm{m}$ \\
& $c_{3}$ & $4.417 \times 10^{3} \mathrm{Ns} / \mathrm{m}$ \\
\hline
\end{tabular}

and TCU-129. It is believed that the natural frequency of the 1 st mode of the structure, which shifted to a lower frequency due to the inertia effect of the damper, is close to the dominant frequency of the input waves of Kobe and TCU-84. It worked enough to suppress vibration in the cases of Kobe and TCU-84, since the inertia effect provided a damping effect. Vibration reduction was more efficient than that in the other cases. The damper worked at a maximum force of about $20 \mathrm{kN}$, and the inertia effect was produced, as shown by the left-rising straight line in Figs. 6(d) - 9(d). The analytical results for the case where the damper is installed are generally close to the experimental results. It is believed that the structural damping is smaller than the real one in the calculations. From Fig. 10, the peak accelerations with the damper installed decrease about 1/2 - 2/3 to that of no damper at every level. Moreover, from Fig. 11, the peak relative displacements decrease about $1 / 2$ to the ones. It was believed that the peak values were increasing linearly to the input level, and all of the tests were performed within the elastic range of the structure. Meanwhile, seismic responses in the case with the damper installed without an inertia effect, i.e., a conventional fluid-type damper, were further simulated in order to evaluate the inertia effect. The peak response values are also shown in Table 3 within brackets. It seems that the maximum displacement grew $10 \%-20 \%$ in the cases of El Centro and TCU-129, which have high frequency domains. Conversely, there is not a great difference between an inertia effect and no inertia effect in the cases of Kobe and TCU-84, which have long period component, since the inertia effect is comparatively useful in a high frequency range. Specifically, the responses at the 3rd story are larger than those in the case with the inertia effect. The maximum force became 1.4 times greater due to the inertia effect. Therefore, it is pointed out that the inertia effect of the damper supports the damping effect. 


\section{Conclusion}

In this paper, a fluid inertia damper with a long spiral bypass pipe was developed and the dynamic properties and vibration reduction for structures were investigated. The primary conclusions can be summarized as follows:

1. A gap that acts as an orifice was spirally formed on the outside of the inner cylinder, and the inner cylinder was inserted into the outer cylinder with an interference fit. By this method, it is possible to make a long and narrow bypass pipe.

2. From the dynamic property tests, the fluid inertia damper can have an inertia force due to the mass of the fluid and a damping force due to the viscosity of the fluid. The friction force is negligibly small.

3. The inertia effect depends on the compression ratio between the cross-sectional areas of the piston and bypass pipe, density of the fluid, and length of the bypass pipe. The inertia force can be derived by using a heavier density of MR fluid.

4. The damping effect in the case of a spiraled bypass pipe is theoretically introduced and becomes a quadratic function related to the velocity.

5. From the seismic vibration tests, the peak accelerations of the damper installed at each story decrease about $3 / 5-1 / 2$ to that of no damper installed, and the peak relative displacements also decrease about $1 / 2-2 / 5$ on average. It is believed that vibration reduction for a seismic motion having a long period component is more effective than that of a wide-band frequency due to the inertia effect.

6. In the dynamic property tests and seismic vibration tests, the experimental results are well matched to the theoretical and analytical results and the validity of the theory and calculations are confirmed.

\section{Acknowledgements}

This study is supported by the Mitsubishi Foundation. The authors would like to express their appreciation to the entire staff of NCREE for their support in the seismic vibration tests.

\section{References}

Chiba, T. and Kobayashi, H., A study on damping characteristics of mechanical snubber, The thermal and nuclear power, Vol. 35, No. 3 (1984), pp. 265-273 (in Japanese).

Dyke, S. J., Spencer, B. F., Sain, M. K. and Carlson, J. D., Modeling and control of magnetorheological dampers for seismic response reduction, Smart Materials and Structures, Vol. 5, No. 5 (1996), pp. 565-575.

Furuhashi, T. and Ishimaru, S., Mode isolation by inertia mass: study on response control by inertial mass No. 1, Journal of Structural and Construction Engineering, Architectural Institute of Japan, Vol. 576 (2004), pp. 55-62 (in Japanese).

Hiramoto, K., Matsuoka, T. and Sunakoda, K., Simultaneous optimal design of the Lyapunov-based semi-active control and the semi-active vibration control device: inverse Lyapunov approach, Transactions of the ASME, Journal of Pressure Vessel Technology, Vol. 134, No. 6 (2012), p. 061211.

Huebscher, R. G., Friction equivalents for round, square and rectangular ducts, American Society of Heating and Ventilating Engineers Transactions, Vol. 54, (1948), pp. 101-118.

Isoda, K., A study on the vibration control damper using power generator with LCR circuit, Summaries of technical papers of Annual Meeting Architectural Institute of Japan, Vol. B-2, No. 21322 (2008), pp. 643-644 (in Japanese).

Ito, H., Pressure Losses in Curved Pipes or in Pipe Bends: A Review of Some Recent Advances, Journal of the Japan Society of Mechanical Engineers, Vol. 62, No. 490 (1959), pp. 1634-1643 (in Japanese).

Ito, H., Flow in curved pipes, Japan Society of Mechanical Engineers, International Journal, Vol. 30, No. 262 (1987), pp. 543-552.

Kato, A. and Ito, M., A proposal of an adjustable mechanical impedance device: an adjustable moment of inertia device, The Transactions of the Institute of Electronics, Information and Communication Engineers, Vol. J73-A, No. 8 (1990), pp. 1399-1405 (in Japanese).

Kawaguchi, O., Kanoh, T., Akino, K., Kato, M. and Sunakoda, K., Research and development of seismic restraint snubbers (I), Journal of Atomic Energy Society of Japan, Vol. 33, No. 1 (1991), pp. 76-89 (in Japanese). 

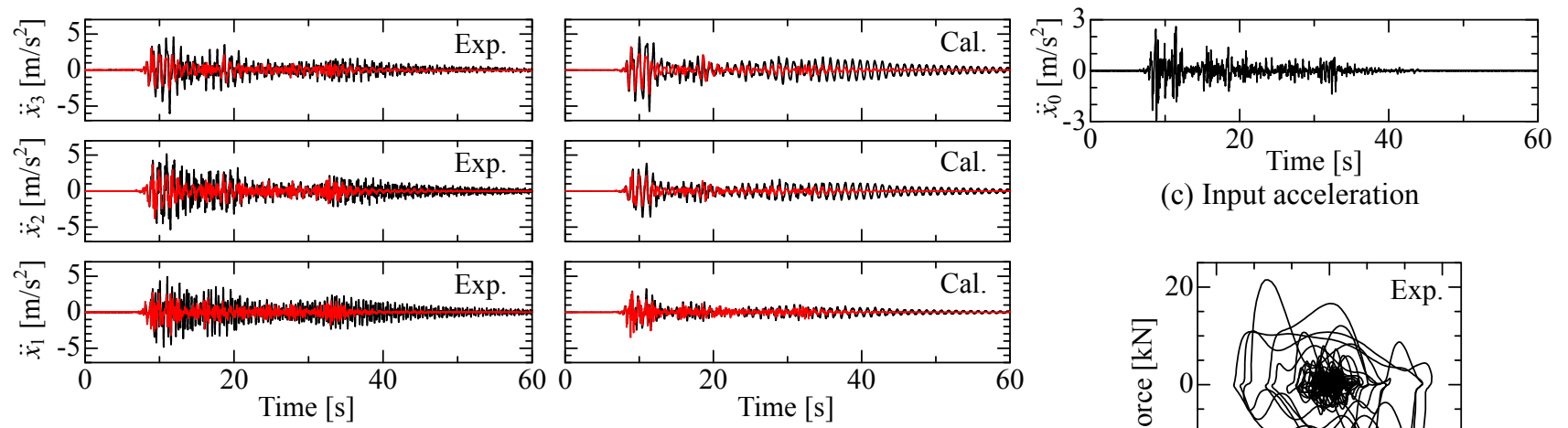

(c) Input acceleration

(a) Acceleration
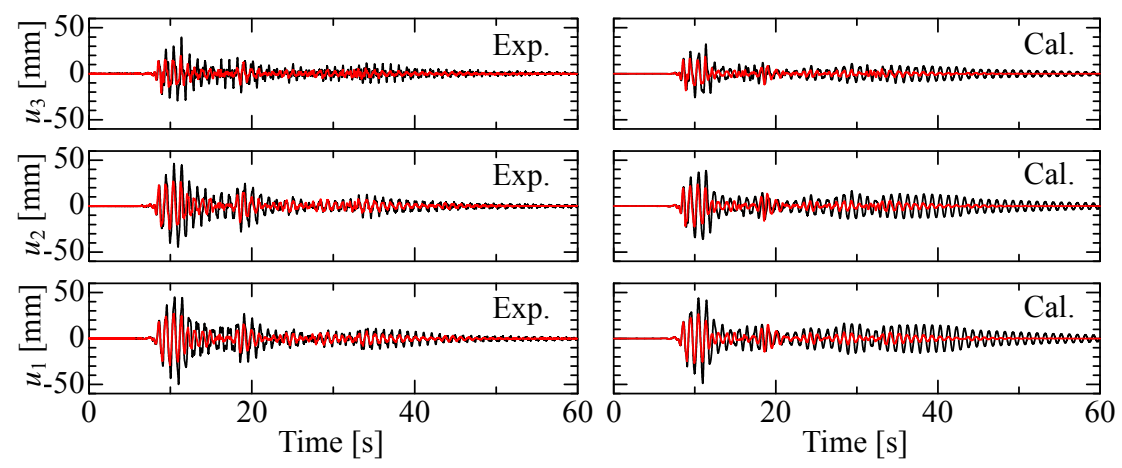

(b) Relative displacement
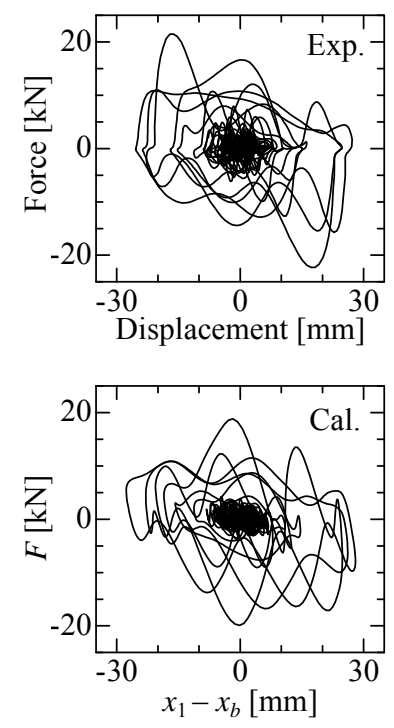

(d) Reaction force

Fig. 6 Seismic response waves in the case of El Centro $3 \mathrm{~m} / \mathrm{s}^{2}$. -: Damper not installed, -: Damper installed. Peak accelerations decrease about $3 / 5-1 / 2$, and displacements decrease about $1 / 2$. Maximum load is $22 \mathrm{kN}$.
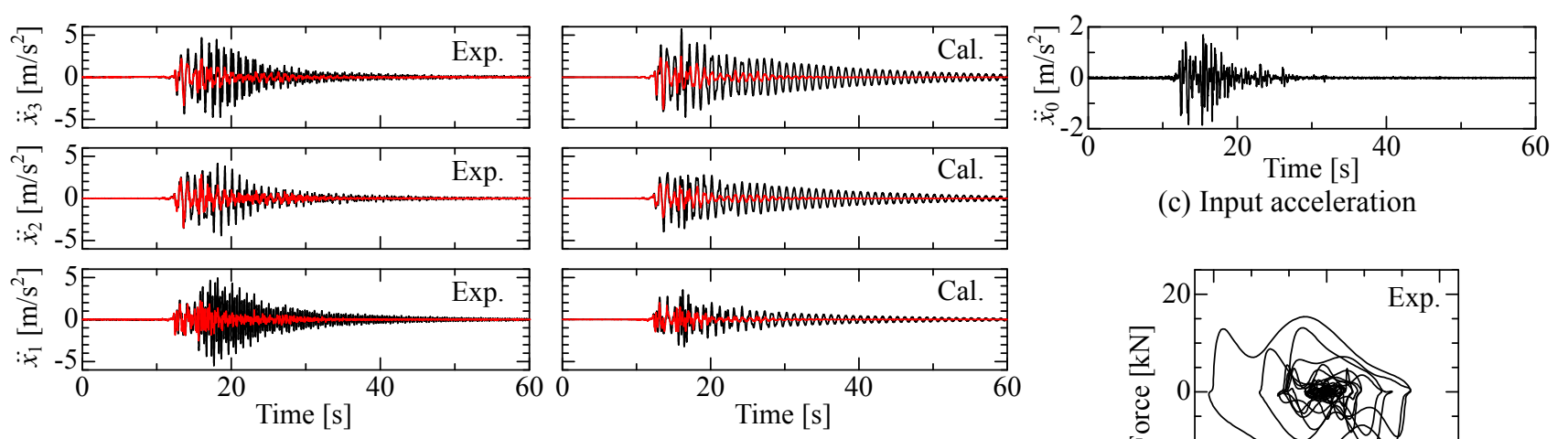

(c) Input acceleration

(a) Acceleration
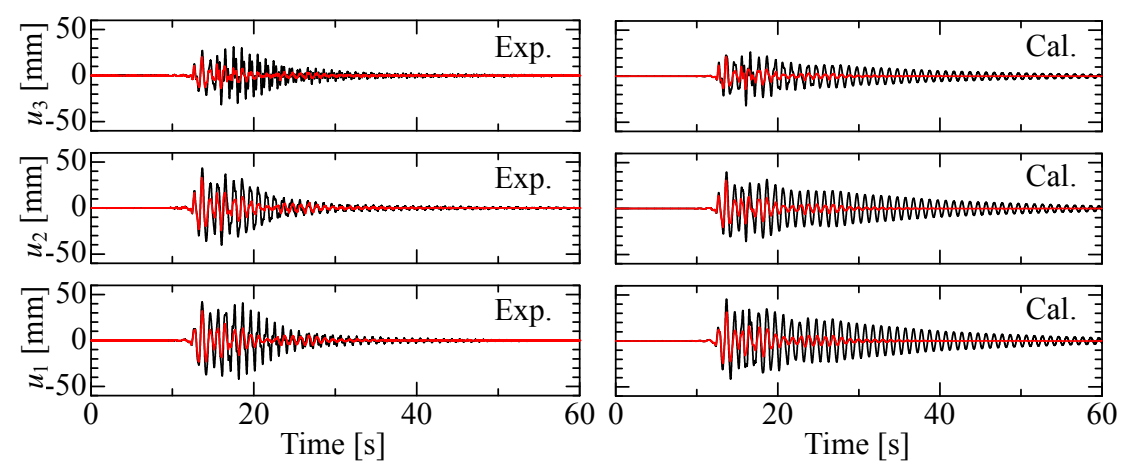

(b) Relative displacement
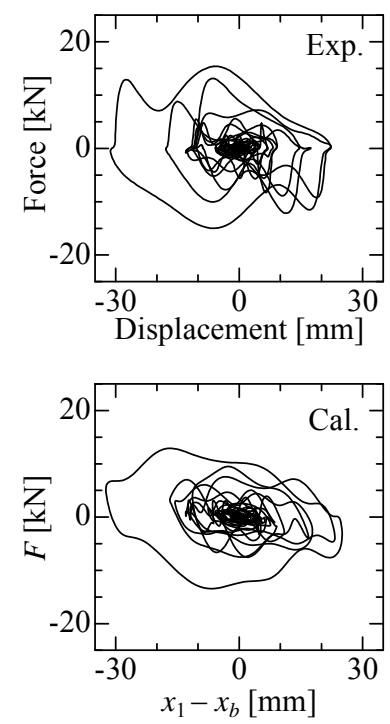

(d) Reaction force

Fig. 7 Seismic response waves in the case of JMA Kobe $2 \mathrm{~m} / \mathrm{s}^{2}$. -: Damper not installed, -: Damper installed. Peak accelerations decrease about $1 / 2$, and displacements decrease about $2 / 3-3 / 4$. Maximum load is $15 \mathrm{kN}$. 

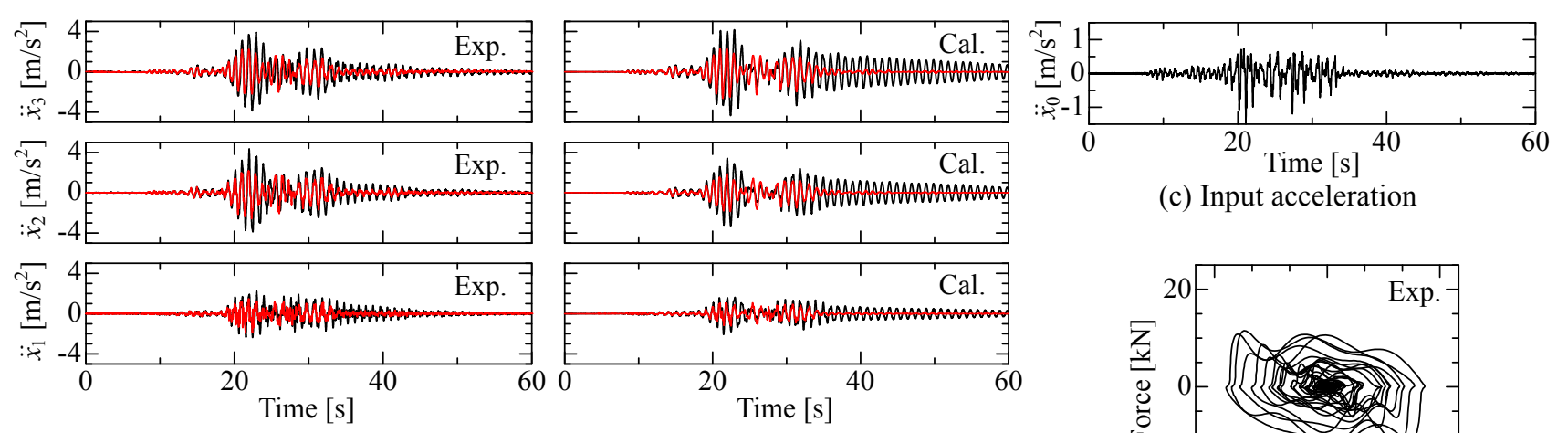

(c) Input acceleration

(a) Acceleration
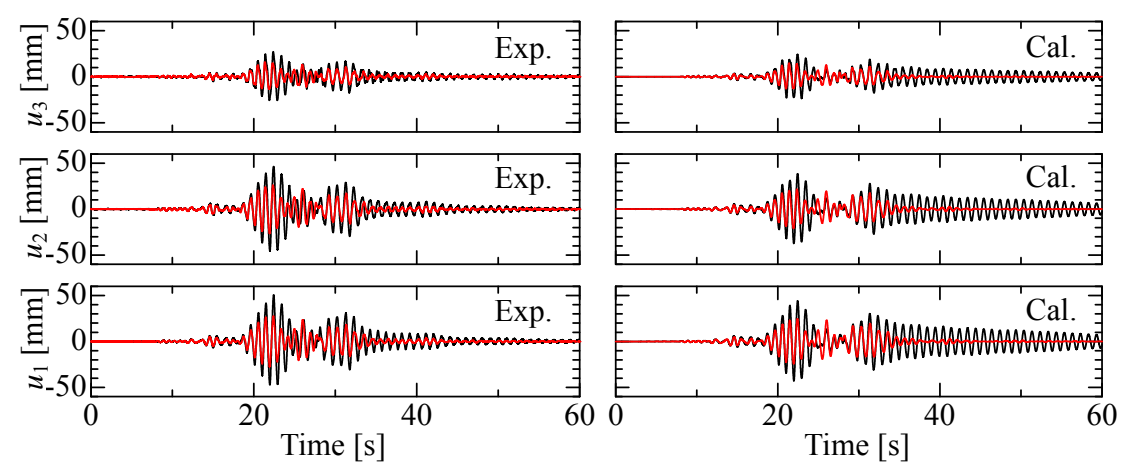

(b) Relative displacement
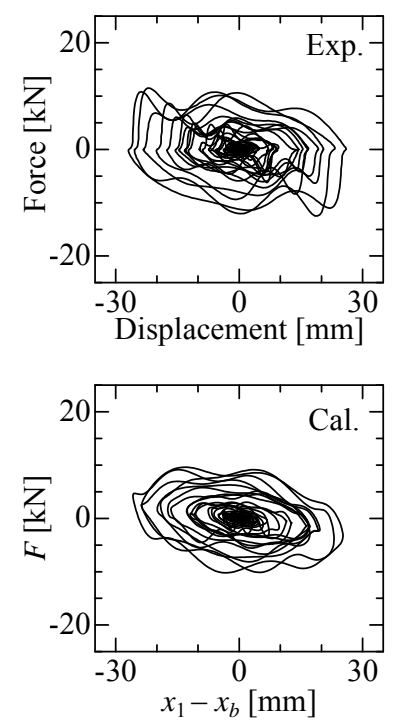

(d) Reaction force

Fig. 8 Seismic response waves in the case of TCU-84 $1.5 \mathrm{~m} / \mathrm{s}^{2}$. -: Damper not installed, -: Damper installed. Peak accelerations decrease about $1 / 2$, and displacements decrease about 2/5. Maximum load is $13 \mathrm{kN}$.
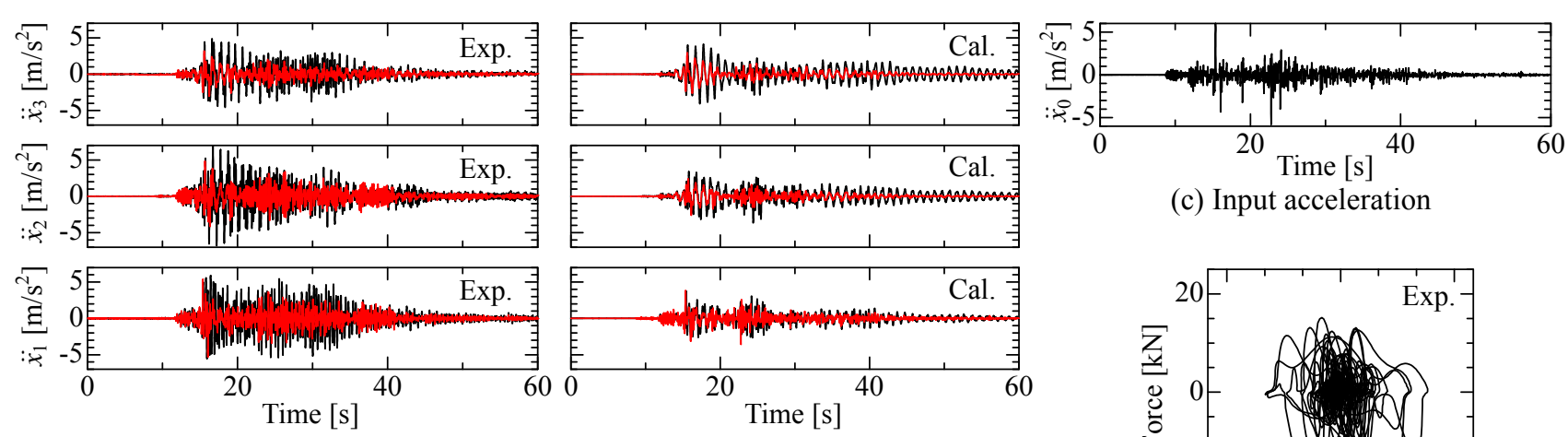

(c) Input acceleration

(a) Acceleration
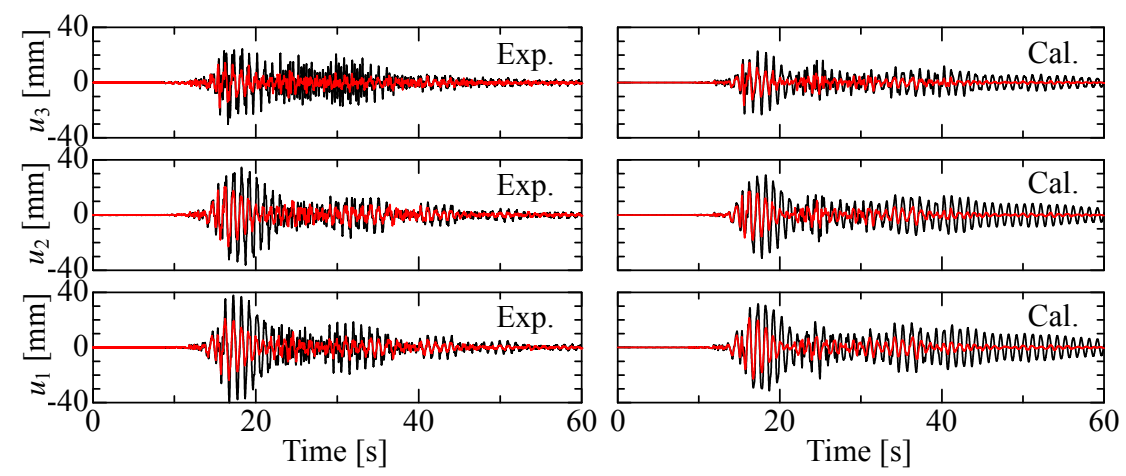

(b) Relative displacement
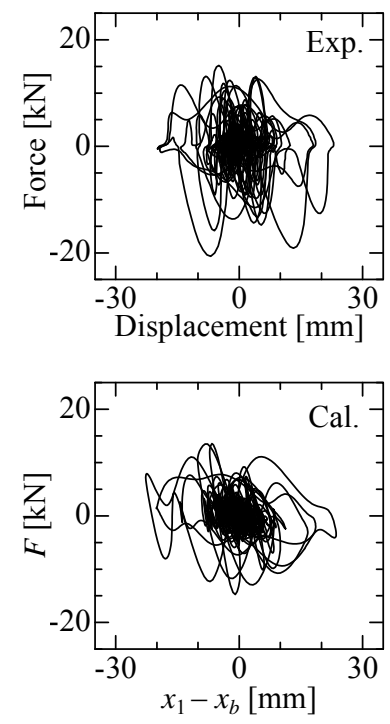

(d) Reaction force

Fig. 9 Seismic response waves in the case of TCU-129 $6 \mathrm{~m} / \mathrm{s}^{2}$. -: Damper uninstalled, -: Damper installed. Peak accelerations decrease about $2 / 3$, and displacements decrease about $1 / 2$. Maximum load is $21 \mathrm{kN}$. 


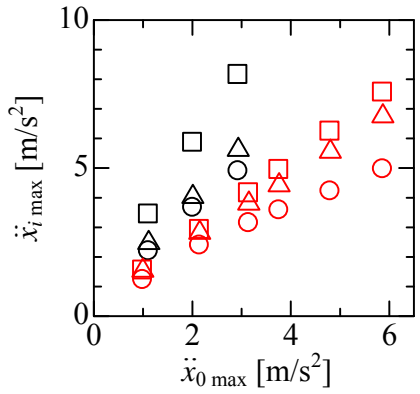

(a) El Centro

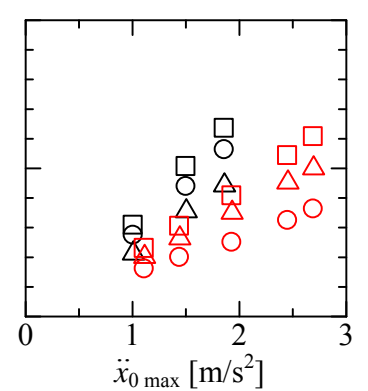

(b) Kobe

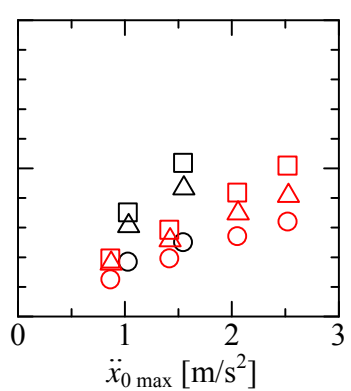

(c) TCU-84

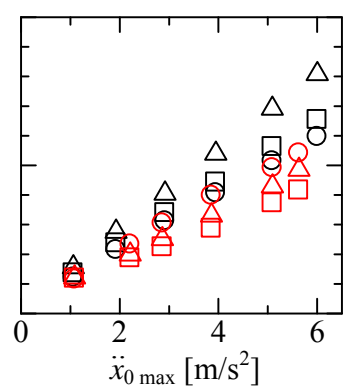

(d) TCU-129

Fig. 10 Peak acceleration of seismic response. $\circ: \ddot{x}_{1}, \Delta: \ddot{x}_{2}, \square: \ddot{x}_{3}$, black is with the damper not installed, red is with the damper installed. Response accelerations increase linearly with the input acceleration.

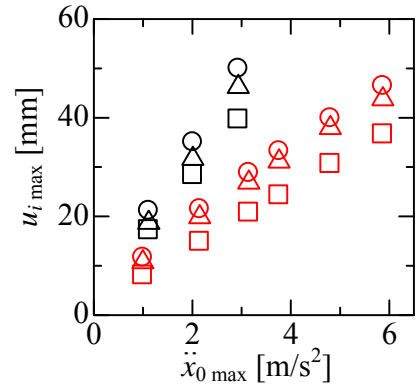

(a) El Centro

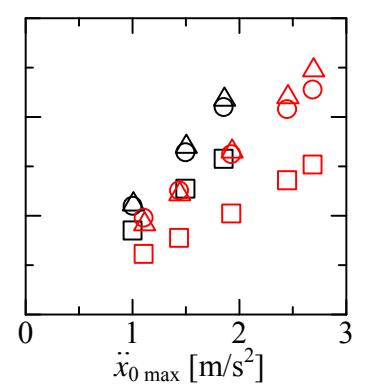

(b) Kobe

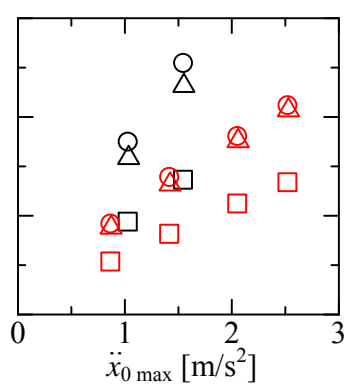

(c) TCU-84

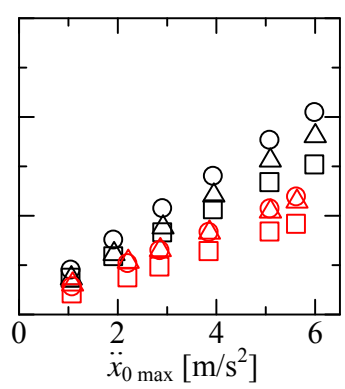

(d) TCU-129

Fig. 11 Peak relative displacement of seismic response. $\circ: u_{1}, \Delta: u_{2}, \square: u_{3}$, black is with the damper not installed, red is with the damper installed. A linear increase means a region of elastic deformation.

Table 3 Comparison of peak values between the experimental and calculated results. Values in brackets are in cases without the inertia effect of the damper.

\begin{tabular}{|c|c|c|c|c|c|c|c|c|}
\hline \multirow{2}{*}{$\begin{array}{l}\text { Input } \\
\text { wave }\end{array}$} & \multirow{2}{*}{ Condition } & \multirow{2}{*}{ Story } & \multicolumn{2}{|c|}{ Acceleration $\left[\mathrm{m} / \mathrm{s}^{2}\right]$} & \multicolumn{2}{|c|}{ Displacement [mm] } & \multicolumn{2}{|c|}{ Force $[\mathrm{kN}]$} \\
\hline & & & Exp. & Cal. & Exp. & Cal. & Exp. & Cal. \\
\hline \multirow{6}{*}{$\begin{array}{l}\text { El Centro } \\
3 \mathrm{~m} / \mathrm{s}^{2}\end{array}$} & \multirow[t]{3}{*}{ Damper not installed } & $1 \mathrm{st}$ & 4.90 & 3.24 & 50.0 & 48.9 & & \\
\hline & & 2nd & 5.62 & 3.85 & 46.2 & 38.6 & & \\
\hline & & $3 \mathrm{rd}$ & 8.15 & 5.73 & 39.7 & 32.2 & & \\
\hline & \multirow[t]{3}{*}{ Damper installed } & $1 \mathrm{st}$ & 3.15 & $3.50(2.65)$ & 28.9 & $26.6(27.6)$ & 22.3 & $19.9(14.1)$ \\
\hline & & 2nd & 3.80 & $2.72(3.16)$ & 26.9 & $23.7(26.3)$ & & \\
\hline & & $3 \mathrm{rd}$ & 4.16 & $3.31(4.01)$ & 20.8 & $18.6(22.5)$ & & \\
\hline \multirow{6}{*}{$\begin{array}{l}\text { Kobe } \\
2 \mathrm{~m} / \mathrm{s}^{2}\end{array}$} & \multirow[t]{3}{*}{ Damper not installed } & $1 \mathrm{st}$ & 5.62 & 3.50 & 41.9 & 45.4 & & \\
\hline & & 2nd & 4.42 & 3.97 & 43.5 & 39.6 & & \\
\hline & & $3 \mathrm{rd}$ & 6.34 & 5.74 & 31.4 & 32.2 & & \\
\hline & \multirow[t]{3}{*}{ Damper installed } & $1 \mathrm{st}$ & 2.49 & $1.99(1.99)$ & 32.3 & $31.1(31.5)$ & 15.4 & $13.4(13.6)$ \\
\hline & & 2nd & 3.51 & $2.28(2.62)$ & 33.0 & $30.6(33.1)$ & & \\
\hline & & $3 \mathrm{rd}$ & 4.06 & $3.80(3.95)$ & 20.3 & $21.3(22.2)$ & & \\
\hline \multirow{6}{*}{$\begin{array}{l}\text { TCU-84 } \\
1.5 \mathrm{~m} / \mathrm{s}^{2}\end{array}$} & \multirow[t]{3}{*}{ Damper not installed } & $1 \mathrm{st}$ & 2.48 & 2.07 & 50.8 & 44.2 & & \\
\hline & & 2 nd & 4.33 & 3.40 & 46.3 & 38.4 & & \\
\hline & & $3 \mathrm{rd}$ & 5.16 & 4.34 & 27.1 & 24.4 & & \\
\hline & \multirow[t]{3}{*}{ Damper installed } & $1 \mathrm{st}$ & 1.94 & $1.19(1.23)$ & 27.7 & $24.7(27.0)$ & 12.5 & $10.2(9.9)$ \\
\hline & & 2nd & 2.58 & $1.89(2.24)$ & 26.4 & $21.5(25.4)$ & & \\
\hline & & $3 \mathrm{rd}$ & 2.90 & $2.63(3.10)$ & 16.2 & $14.8(17.4)$ & & \\
\hline \multirow{6}{*}{$\begin{array}{l}\text { TCU-129 } \\
6 \mathrm{~m} / \mathrm{s}^{2}\end{array}$} & \multirow[t]{3}{*}{ Damper not installed } & $1 \mathrm{st}$ & 5.97 & 3.72 & 40.9 & 31.6 & & \\
\hline & & 2nd & 8.08 & 3.66 & 36.1 & 31.1 & & \\
\hline & & $3 \mathrm{rd}$ & 6.54 & 4.13 & 30.2 & 23.2 & & \\
\hline & \multirow[t]{3}{*}{ Damper installed } & $1 \mathrm{st}$ & 5.42 & $3.81(3.78)$ & 23.7 & $22.7(22.8)$ & 20.6 & $14.7(10.8)$ \\
\hline & & 2nd & 4.85 & $2.54(3.08)$ & 22.9 & $18.2(20.1)$ & & \\
\hline & & $3 \mathrm{rd}$ & 4.16 & $2.93(3.57)$ & 18.2 & $16.4(20.0)$ & & \\
\hline
\end{tabular}


Kawamata, S. and Onuma, M., Control of structural vibration by inertia pump damper: part (1) theoretical model and response to harmonic excitation, Summaries of technical papers of Annual Meeting Architectural Institute of Japan, No. 2386 (1986), pp. 771-772 (in Japanese).

Matsuoka, T., Sunakoda, K., Hiramoto, K. and Ohtake, T., Study on vibration control device using power generator, Transactions of the Japan Society of Mechanical Engineers, Series C, Vol. 73, No. 735 (2007), pp. $2926-2931$ (in Japanese).

Matsuoka, T. and Sunakoda, K., Vibration suppression device that utilizes inertia mass by fluid, Transactions of the Japan Society of Mechanical Engineers, Series C, Vol. 75, No. 759 (2009), pp. 2893-2898 (in Japanese).

Matsuoka, T., Vibration suppression device having variable inertia mass by MR-fluid, ASME, International Design Engineering Technical Conferences \& Computers and Information in Engineering Conference 2011 (2011), Paper No. 47020.

Nakamura, M., Takewaki, I., Yasui, Y. and Uetani, K., Simultaneous identification of stiffness and damping of building structures using limited earthquake records, Journal of structural and construction engineering, Architectural Institute of Japan, No. 528 (2000), pp. 75-82 (in Japanese).

Nakamura, Y., Fukukita, A., Tamura, K., Yamazaki, I., Matsuoka, T., Hiramoto, K. and Sunakoda, K., Seismic response control using electromagnetic inertial mass dampers, Earthquake Engineering \& Structural Dynamics, Vol. 43, No. 4 (2014), pp. 507-527.

Ohmata, K. and Miyanaga, H., Study on a mechanical snubber with adjustment mechanism for resisting force, Transactions of the Japan Society of Mechanical Engineers, Series C, Vol. 57, No. 534 (1991), pp. $466-471$ (in Japanese).

Okumura, A. Japanese Patent No. 3718683 (2005).

Saito, K., Kurita, S. and Inoue, N., Optimum response control of 1-DOF system using linear viscous damper with inertial mass and its kelvin-type modeling, Journal of structural engineering, Architectural Institute of Japan, Vol. 53B (2007), pp. 53-66 (in Japanese).

Shimizu, Y., Sugino, K., Kuzuhara, S. and Murakami, M., Hydraulic losses and flow patterns in bent pipes: Comparison of the results in wavy pipes and quasi-coiled ones, Bulletin of JSME, Vol. 25, No. 199 (1982), pp. 24-31.

Sodeyama, H., Suzuki, K., Iwata, N. and Sunakoda, K., A study on design method of the bypass type MR damper, Transactions of the Japan Society of Mechanical Engineers, Series C, Vol. 70, No. 691 (2004), pp. 625-632 (in Japanese).

Spencer, B. F., Dyke, S. J., Sain, M. K. and Carlson, J. D., Phenomenological model for magnetorheological dampers, Journal of Engineering Mechanics, Vol. 123, No. 3 (1997), pp. 230-238.

Sunakoda, K. and Matsuoka, T., Vibration tests of a cut-off system using water and functional fluids, ASME, Pressure Vessels and Piping Conference 2006 (2006), Paper No. 93532.

Sunakoda, K., Matsuoka, T., Hiramoto, K. and Fukukita, A., Electromagnetic vibration control device applicable to twin mode of semiactive and passive types, Transactions of the Japan Society of Mechanical Engineers, Series C, Vol. 75, No. 758 (2009), pp. 2659-2664 (in Japanese).

Teramura, A. and Yamaguchi, T., Japanese Unexamined Patent Application Publication No. Hei 11-108099 (1999).

Ullman. D. and Velkoff, H., An introduction to the variable inertia flywheel, Transaction of ASME, Journal of Applied Mechanics, Vol. 46, No. 1 (1979), pp. 186-190.

Yang, G., Spencer, B. F., Carlson, J. D. and Sain, M. K., Large-scale MR fluid dampers: modeling and dynamic performance considerations, Engineering Structures, Vol. 24 (2002), pp. 309-323. 